\title{
Review
}

\section{Gut microbiome and aging: Physiological and mechanistic insights}

\author{
Ravinder Nagpal ${ }^{\mathrm{a}}$, Rabina Mainali ${ }^{\mathrm{a}}$, Shokouh Ahmadia, ${ }^{\mathrm{a}}$, Shaohua Wang ${ }^{\mathrm{a}}$, Ria Singh ${ }^{\mathrm{a}}$, \\ Kylie Kavanagh ${ }^{c}$, Dalane W. Kitzman ${ }^{\mathrm{d}}$, Almagul Kushugulova ${ }^{\mathrm{e}}$, Francesco Marotta ${ }^{\mathrm{f}}$ \\ and Hariom Yadav ${ }^{\mathrm{a}, *}$ \\ ${ }^{a}$ Center for Obesity, Diabetes and Metabolism (Internal Medicine-Molecular Medicine), Wake Forest School of \\ Medicine, Winston-Salem, NC, USA \\ ${ }^{\mathrm{b}}$ Department of Food Science and Technology, College of Agriculture, Isfahan University of Technology, Isfahan, \\ Iran \\ ${ }^{\mathrm{c}}$ Department of Pathology (Comparative Medicine), Wake Forest School of Medicine, Winston-Salem, NC, USA \\ ${ }^{\mathrm{d}}$ Gerontology and Geriatric Medicine, Wake Forest School of Medicine, Winston-Salem, NC, USA \\ ${ }^{\mathrm{e}}$ Center for Life Sciences, NLA, Nazarbayev University, Astana, Republic of Kazakhstan \\ ${ }^{\mathrm{f}}$ ReGenera Research and Development for Aging Interventions, and San Babila Clinic, Corso Matteotti 1/A, \\ Milano, Italy
}

\begin{abstract}
The development of human gut microbiota begins as soon as the neonate leaves the protective environment of the uterus (or maybe in-utero) and is exposed to innumerable microorganisms from the mother as well as the surrounding environment. Concurrently, the host responses to these microbes during early life manifest during the development of an otherwise hitherto immature immune system. The human gut microbiome, which comprises an extremely diverse and complex community of microorganisms inhabiting the intestinal tract, keeps on fluctuating during different stages of life. While these deviations are largely natural, inevitable and benign, recent studies show that unsolicited perturbations in gut microbiota configuration could have strong impact on several features of host health and disease. Our microbiota undergoes the most prominent deviations during infancy and old age and, interestingly, our immune health is also in its weakest and most unstable state during these two critical stages of life, indicating that our microbiota and health develop and age hand-in-hand. However, the mechanisms underlying these interactions are only now beginning to be revealed. The present review summarizes the evidences related to the age-associated changes in intestinal microbiota and vice-versa, mechanisms involved in this bidirectional relationship, and the prospective for development of microbiota-based interventions such as probiotics for healthy aging.
\end{abstract}

Keywords: Aging, enteric nervous system, gut dysbiosis, gut permeability, intestinal microbiota, metabolic inflammation, probiotics, prebiotics

\footnotetext{
${ }^{*}$ Corresponding author: Hariom Yadav, PhD., Center for Diabetes, Obesity and Metabolism (Internal Medicine-Molecular Medicine), Wake Forest School of Medicine, Department of Microbiology and Immunology, Biotech Place, Suite 2E-034, 575 Patterson Ave., Winston-Salem, NC 27101, USA. Tel.: +1 336713 5049; Fax: +1 336716 9928; E-mail: hyadav@wakehealth.edu.
}

5-HT
AMP
CNS
CRP
DC
Abbreviations 


$\begin{array}{ll}\text { E. coli } & \text { Escherichia coli } \\ \text { ENS } & \text { enteric nervous system } \\ \text { IBD } & \text { inflammatory bowel disease } \\ \text { IL } & \text { interleukins } \\ \text { IL-6 } & \text { Interleukine-6 } \\ \text { IL-8 } & \text { Interleukine-8 } \\ \text { IR } & \text { insulin resistance } \\ \text { LBP } & \text { LPS-binding protein } \\ \text { LPS } & \text { lipopolysaccharide } \\ \text { pIgR } & \text { polymeric immunoglobulin receptor } \\ \text { SCFA } & \text { short-chain fatty acids } \\ \text { SIgA } & \text { secretory immunoglobulin A } \\ \text { T2D } & \text { type } 2 \text { diabetes } \\ \text { Th17 } & \text { T-helper 17 } \\ \text { TLR } & \text { toll-like receptors } \\ \text { TNF- } \alpha & \text { tumor necrosis factor-alpha. }\end{array}$

\section{Introduction}

Aging is a highly complex process affecting a wide array of physiological, genomic, metabolic, and immunological functions $[1,2]$. For decades, it has been known that the aging process involves attenuation of the host's ability to sustain a robust and efficient immune response and metabolic health. However, only recently have progresses in cellular and molecular research enabled us to more clearly understand the various core mechanisms and hallmarks (e.g. senescence i.e. the progressive impairment of cellular/physiological functionalities) that underlie the complex processes of age-associated disturbances in immune system such as inflammation and metabolic dysfunctions. Indeed, these disturbances may be one of the primary risk factors for age-related increased predisposition to various chronic maladies including cardiovascular disorders, infections, bowel diseases, autoimmune diseases, cancers, diabetes, obesity and neurodegenerative diseases [2]. As a result, aging research has experienced an extraordinary progress over recent years, particularly with the speculations that the process of aging could be controlled by maintaining the homeostasis of various genetic, biochemical and immunological processes [3]. Interestingly, many clinical issues, such as concomitant exposure to multiple drugs/antibiotics, dietary modifications and constipation, that generally accompany senescence are also closely correlated with perturbations in gut microbiome composition and functions [4]. Given that the gut microbiome is closely associated with several features of gut barrier integrity, intestinal

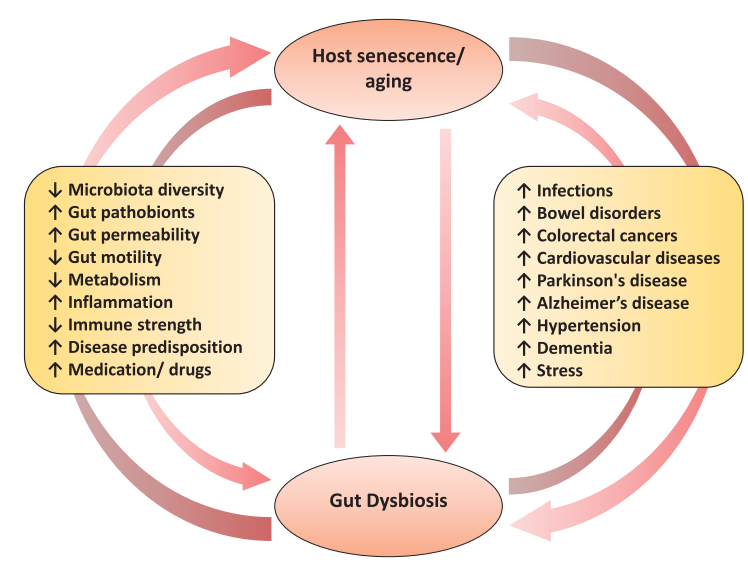

Fig. 1. The two-way connection between human gut microbiome and host aging, and the potential underlying and/or associated elements.

pro- and anti-inflammatory balance, immune and cardio-metabolic health, and gut-brain axis [5, 6], these old-age-related clinical issues could clearly contribute to the increased predisposition to various infectious and gut-associated diseases by causing alterations in the microbiota of elderly people (Fig. 1). In a nutshell, these evidences suggest that the gut microbiota may be associated with inflammaging and age-related chronic health conditions, and hence could be exploited as a putative target to ameliorate the aging process $[7,8]$.

The recent advent of high-throughput gene sequencing tools has also revealed that our genome encompasses an almost equivalent number of human (eukaryotic) and microbial (prokaryotic) genes [9], thereby instigating a paradigm shift for microbiometargeted prognostic, diagnostic as well as therapeutic medicine. Notably, genomic instability is a common denominator of senescence $[1,8,10]$; however, we still do not have a complete understanding of the mechanisms underlying the aging-mediated changes in the gut microbiome configurations, or whether these microbial changes are the cause or consequence of senescence. In these contexts, we herein aim to present an overview of the features of the gut microbiome that have been implicated in the process of human aging. To accomplish this, we have ontologically divided the review into: (a) a brief outline of the gut microbiota development; (b) an overview of ageinduced changes in the microbiota; (c) a discussion of potential implication of microbiota changes in the senescence of immune and inflammatory health; and (d) an outline of potential microbiota-targeted therapies for amelioration of human aging. We finally conclude with a discussion of the prospective impli- 
cations of this age-associated alternations in the gut microbiota, with specific regard to ameliorating the senescence and postponing the ill-health of old-age in order to improve the human health and disease in old-age.

\section{Development of human gut microbiota: Who's born first, baby or its microbiome?}

The microbial colonization of the human gut begins at birth and immediately thereafter; but some recent studies reporting the presence of bacteria in placenta, amniotic cavity, umbilical cord, and meconium have suggested that the dynamic and complex process of infant microbiota colonization may have already started in-utero [11-18]. In any case, it is well acknowledged that the foundational microbiota configuration keeps on fluctuating markedly during infancy, especially during the first three years, until finally settling into a somewhat stable structure resembling that of adult-microbiota [15-23]. The composition of this primitive intestinal microbiota is influenced by various elements, such as mode of delivery and feeding, antibiotic exposure, maternal diet and microbiota, surrounding environment [16, 17, 20-22, 24-26] (Fig. 2). It has been reported that vaginally delivered babies have an early and enriched colonization of lactobacilli, bacteroides, and Prevotella which are mostly acquired from maternal vaginal and fecal microbiota during birth; whereas cesarean-born infants have a delayed or lower carriage of bacteroides, bifidobacteria, and lactobacilli and are more often colonized with Clostridium (C.) difficile, C. perfringens, and Escherichia (E.) coli $[15,17,20-22,24,27]$. Also, infants treated with antibiotics are found to have lower carriage of lactobacilli, bifidobacteria, and enterococci $[22,24]$. However, differences in the microbiota of cesareanborn infants can be ascribed to the overlapping effects of several factors such as evaded contact with mother's vaginal and fecal microbiota, longer stay in the hospital, more chances of acquiring 'hospital' microflora, longer antibiotic regimen. After birth, the mode of feeding is another important factor impacting the gut microbiota development. While breast-fed babies are found to have more bifidobacteria, lactobacilli, staphylococci, and streptococci; formula-fed infants show higher colonization of Bacteroides, clostridia and proteobacteria [22, 28].

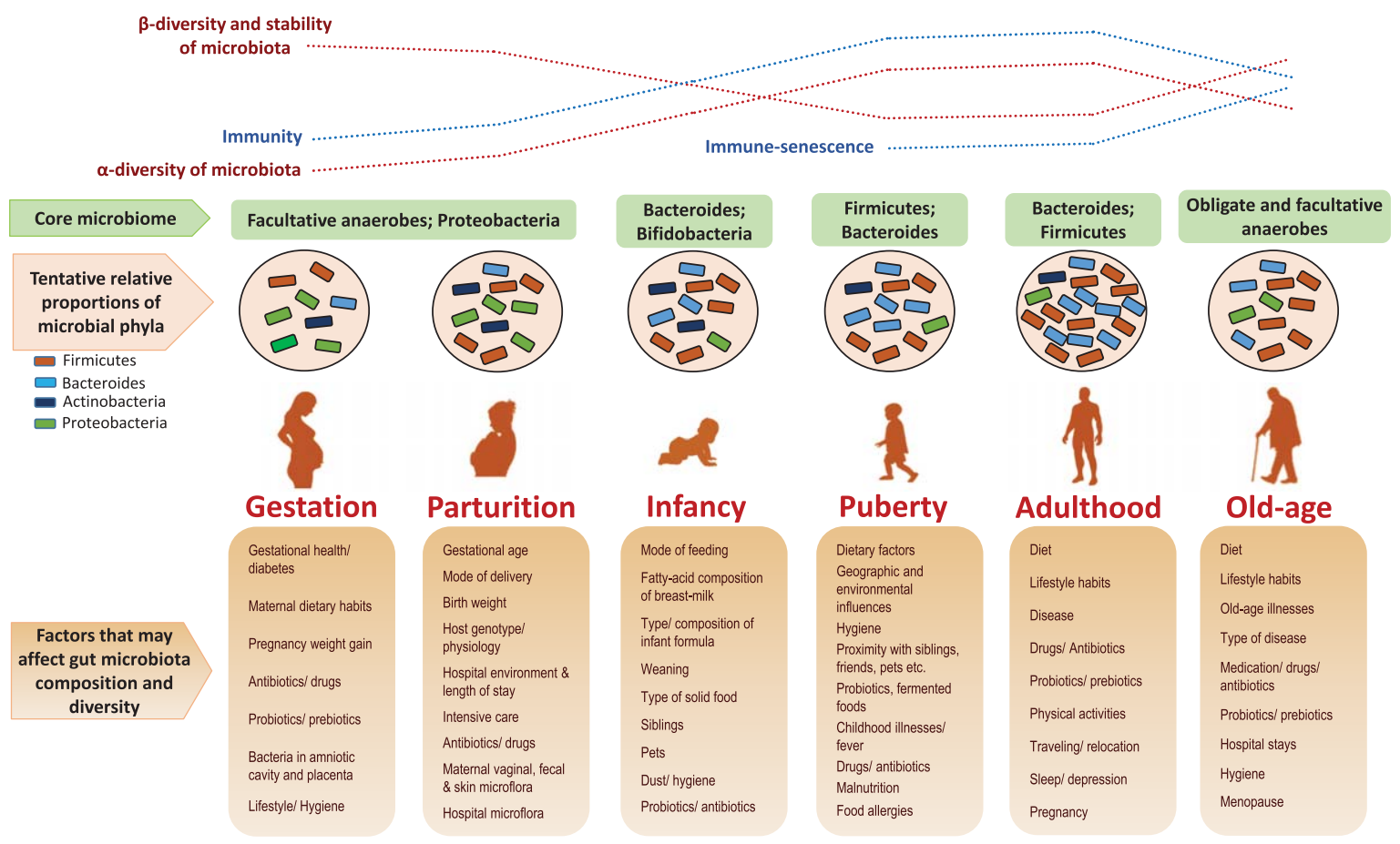

Fig. 2. Age-related changes in the human gut microbial ecosystem, and potential factors that could affect microbiota composition at different stages of life. $\alpha$-diversity: species (taxa) richness within a single host/microbial environment; $\beta$-diversity: diversity in microbial community (taxonomic abundance profiles) between different environments/samples) [4, 23, 31, 34, 73]. 
However, these differences begin to diminish and the overall gut microbiota composition starts getting relatively stable at weaning i.e. after introducing solid foods in babies' diet [20, 21, 28]. Nevertheless, from this stage onwards, diet becomes the major factor that strongly influences the subsequent maturation and maintenance of gut microbiota configuration throughout the lifespan [29, 30] (Fig. 2).

\section{Gut microbiota and senescence: Growing older together}

Gut microbes do not age per se, but the incidences of comorbidities associated with gut microbiota tend to increase as the host grows older [8, 31]; even though it remains unclear whether microbiota alterations are cause or consequence of host aging (Fig. 2). It is found that elder people have a different gut microbiota profile compared to healthy adults, and this difference could be attributed to several reasons associated with senescence, such as changed lifestyle and dietary schedule, lesser mobility, weakened immune strength, reduced intestinal and overall functionality, altered gut morphology and physiology, recurrent infections, hospitalizations, and use of medications, etc. [23, 32-36] (Figs. 1 and 2). Generally, the diversity of gut microbiota and the carriage of commensals such as bacteroides, bifidobacteria and lactobacilli are found to be reduced while the levels of opportunists such as enterobacteria, C. perfringens and $C$. difficile are increased in elderly [23, 33, 36-41]. However, these aging-associated changes in the gut microbiota may vary according to the geographical location since dissimilar results have been observed in elderly populations from different locations [40, 42-45]. While it remains unknown if this gut dysbiosis is a cause or consequence of aging and senescence-associated inflammatory disorders; it has been hinted that gut microbiota homeostasis is crucial for healthy aging and hence restoration of this homeostasis might be supportive for human longevity $[8,35,46]$. Nevertheless, given that the gut microbiota has a strong impact on numerous aspects of host health and that the aberrations in the microbiota diversity and functionality are associated with various inflammatory conditions, it appears plausible to look at the human biology from a microbiota perspective as well and to envisage certain microbiota deviations as hallmarks of aging process.
Besides microbiota diversity, reduced microbiotarelated metabolic capacity, such as lower short-chain fatty acids (SCFAs) levels, in old age may also be associated with aging-related maladies such as irregular bowel transit, reduced appetite, frailty, weight loss, cognitive decline, hypertension, vitamin D deficiency, diabetes, arthritis, sarcopenia, etc. [47-50]. Given that the gut commensal bacteria have significant influence on host nutrition and metabolism and that the microbiota-derived metabolites viz. SCFAs are readily absorbed in the plasma of the host via the intestinal epithelium, it can also be speculated that gut microbiota-derived metabolites may have important effect on human longevity [51-54]. One fascinating example of microbiota-metabolite-mediated effect on longevity is Metformin, the most commonly prescribed treatment for metabolic disease, which has also received attention as a prospective anti-aging or pro-longevity molecule $[1,55]$. Intriguingly, this pro-longevity effect has been found to be indirectly mediated by its influence on bacteria [56], specifically involving the suppression of bacterial folate metabolism $[1,57]$, thereby highlighting the importance of exploring the possible pro-longevity effect of such drugs and also elucidating how microbiota and microbial-metabolites play a role in antiaging effects [58]. In addition, elderly people have elevated serum levels of IL-6 and CRP [59]. Interestingly, maintaining a balanced nutrition and physical activity has been found to be beneficial for cognitive decline, sarcopenia, weight loss, and other maladies related to aging $[60,61]$, further hinting at the potential of gut microbiota-metabolite-based interventions for healthier aging.

\section{Aging of the microbiota-immune interface: An intimate affair}

The gut microbiota plays a central role in various host physiological functions including degradation of fibrous foods, energy supply and harvest, lipid storage and metabolism, synthesis of vitamins, suppression of harmful bacteria and maintenance of intestinal barrier integrity [62]. It is also well established that intestinal microbiota plays a vital role in the development and expansion of gut mucosal and systemic immune system [63, 64]. In fact, the intestinal mucosa is the largest surface area of human body which comes in direct contact with the foreign/environmental antigens. The immune cells of mucosal immune system - which is stretched throughout the length 
of gastrointestinal tract - harbor a wide array of pattern-recognition receptors (e.g. Toll-like receptors) and are in active cross-talk with the rest of immune system through the local mesenteric lymph nodes [63]. The gut mucosa-associated immune system performs several important functions of which the most important ones are (a) tolerating the overlaying microbiota thereby preventing any harmful induction of systemic immune responses, and (b) controlling the overall gut microbiota thereby preventing the unsolicited growth of microorganisms and their translocation to other bodily locations [65-67]. The role of gut microbiota in immune development and functions has been revealed in several studies on germ-free animal models. It has been shown that the numbers and populations of several important immune cells are reduced, and several local and systemic lymphoid structures are impaired in germfree animals [68]. Treating germ-free animals with specific bacteria or bacterial components has been found to restore the development of various important immune cells [69]. Specific bacteria belonging to Bacteroides and Lactobacillus have also been revealed to participate in the regulation of Th17 cells [70] and dendritic cells [71], respectively. Interestingly, it has also been discovered that the phenotypes of majority of gut mucosa-associated immune cells are different from systemic immune cells, even if these are of same lineage [72], which might possibly be a natural physiological mechanism required for supporting a more tolerogenic gut environment (Fig. 3A).

Although the evidences of direct association between gut microbiota and host chronological aging are still limited [8, 36, 73], but a reduced gut microbiota diversity has been speculated to be associated with increased old-age frailty [23, 31, 74, 75]. Another observation supporting the link between gut microbiota and immunity, especially in old age, can also be supported by the observations that the intestinal commensal bacteria (e.g. bifidobacteria, lactobacilli, bacteriodes) generally found to be reduced in aged people, that maintain immune tolerance in the gut $[34,76]$. Whereas most of the opportunistic bacteria whose numbers are generally elevated with age are known to stimulate intestinal inflammation [77, 78]. Together, these observations again hint that maintaining the gut microbiota homeostasis could be beneficial for maintaining gut and overall health, whereas perturbations in gut microbiota could upset several features of host health $[7,8$, 74, 75, 79] (Fig. 3B).
Our microbiota influences various features of not only our intestinal but also systemic immune and inflammatory components [80], suggesting that agerelated deteriorations in immune-modulatory status (the so-called immune-aging or immune-senescence or inflammaging) [81]. For example, increased levels of TNF, IL-6 and IL-8 in old-age may be associated with changes in gut microbiota $[34,82,83]$. Nevertheless, it still remains to be deciphered if these associations are direct or indirect, or if age-related alterations in microbiota cause immune-senescence or it's the other way around (Fig. 2). However, it can be speculated that the gut epithelium that acts as a barrier between gut microbes and systemic circulation, might be playing a role in the association of microbiota and inflammaging $[84,85]$. For example, declined integrity of intestinal epithelium in old age could instigate more leakage of gut bacteria in the systemic circulation eventually leading to an increased antigenic load and systemic immune activation which might represent a hallmark of old-age ailments including autoimmune disorders, liver disease, and cardiovascular and neurologic conditions [36, 86-88] (Fig. 3).

\section{Gut microbiome and aging-related metabolic diseases}

With an aging population worldwide, the prevalence of metabolic diseases has also radically increased. Dysbiosis in gut microbiome and microbial metabolites is known to be associated with aberrations of gut barrier integrity and enhanced proinflammatory cytokines; and all these elements can also potentially or partly underlie the pathogenesis and progression of various metabolic diseases that are prevalent in old people such as adiposity, insulin resistance, fatty liver and hepatic steatosis, atherosclerosis, cardiovascular diseases, and diminished motor activity [53, 89]. Alterations in the aging gut microbiome can also impact gut-brain axis thereby hampering neural, endocrine, nutrient, and immunological signals between gut and brain via enteric nervous system (ENS) and could play a role in diseases of the central nervous system (CNS) such as multiple sclerosis, autism, depression, anxiety $[90,91]$. Such aging-associated alterations in gut microbiome may not necessarily be triggered by aging, but they might be linked with the common deterioration in the health status accompanied by malnutrition and inclined need for medications 


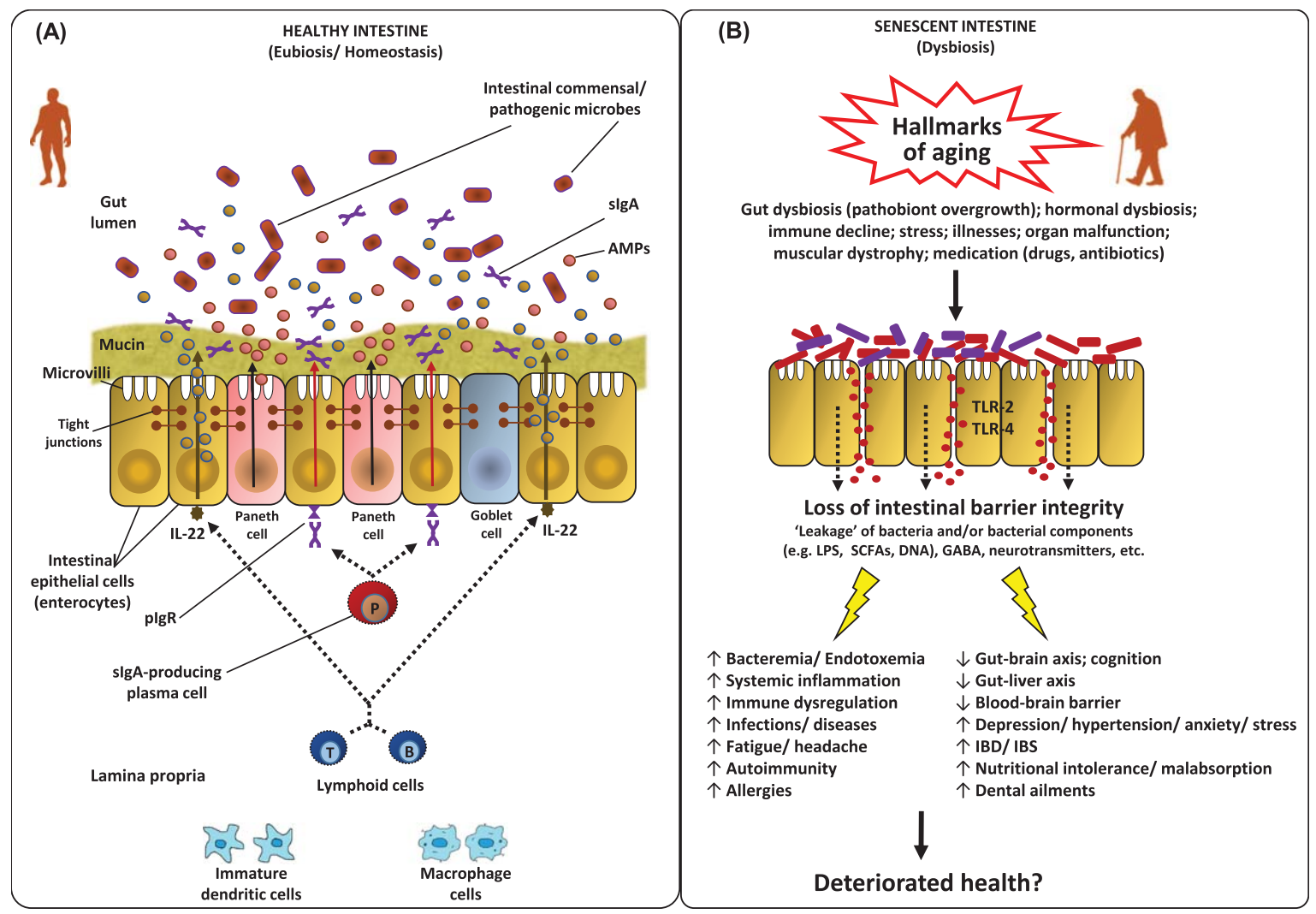

Fig. 3. Features of the homeostatic intestinal environment (eubiosis) (A), and how a perturbed microbiota (dysbiosis) and gut barrier may instigate aging-related maladies (B). Under homeostatic conditions (eubiosis), the epithelial cells produce antimicrobial peptides (AMPs) in response to interleukins (e.g. IL-22) and also express pattern recognition receptors (e.g. Toll-like receptors; TLR). The gut microbes regulate mucous secretion and AMPs production and also regulate/enhance the gut barrier integrity via producing short-chain fatty acids (SCFAs). Goblet cells produce mucus to constrain pathobiont invasion. Lymphoid cells (e.g. $\mathrm{T}_{\mathrm{H}} 17$ cells) play a role in host defense by producing controlled arrays of IL-22. Dendritic cells (DCs) induce the activation and differentiation of naive B cells to produce plasma cells that produce commensal-specific $\operatorname{IgA}$ in the lamina propria. $\operatorname{IgA}$ is transported into the gut lumen as secreted $\operatorname{IgA}(\operatorname{Ig} \mathrm{A})$ via (polymeric immunoglobulin receptor $\mathrm{pIgR}$ ) receptors, where after sIgA binds to commensal microbes and soluble antigens, thereby restraining their adherence to the host epithelium and leakage through the gut barrier. However, under dysbiosis and/or senescent milieus, the altered microbiota composition and weakened/perturbed gut permeability may lead to increased adherence and leakage of various microbes and microbial by-products through the gut barrier thereby instigating hyper-inflammatory responses eventually increasing the host susceptibility to various gut-related as well as systemic ailments via perturbations in the magnitude of gut-brain axis, gut-liver axis etc. [7, 36, 63, 84, 124, 127, 128, 132, $133,147]$.

including non-steroidal anti-inflammatory drugs, antibiotics etc. Several studies have speculated that the loss of microbiome diversity is rather correlated with aging-related frailty than with chronological age per se [31, 92]. The age-related perturbations in the gut microbiome are also shown to be an important contributing factor of age-associated pathological states such as chronic inflammation [93], neurodegeneration [94], diabetes [95], non-alcoholic fatty liver disease and cardiovascular disease [96]. The mechanisms by which the gut microbiome may favorably influence host aging are now being intensively studied while exploring safe and effective approaches (such as dietary therapies including probiotics, fiber ingredients, nutraceuticals and others) to improve/restore gut eubiosis for better health. Among these mechanisms, the direct modulation of gut microbiome that could diminish inflammatory responses and ameliorate adaptive immune responses is major pathway to stabilize immunosenescence. Other mechanisms purportedly facilitating these effects include augmentation of antioxidant activity, regulation of host fat deposition and metabolism, suppression of insulin resistance, improvement of mucosal barrier integrity and immune homeostasis, elevated production of SCFAs, alleviating gut 
peptides involved in lipid metabolism and glucose homeostasis, and also up-regulation of particular genes involved in xenobiotic metabolism [92].

\section{Enteric nervous system in relation to host senescence}

The ENS is made up of the extensive network of morphologically and functionally diverse subpopulations of neurons that are clustered into the networks of small ganglia and are dispersed profusely across the length of the gastro-intestinal tract membrane. ENS is undoubtedly the largest and the most complex component of the peripheral nervous system in the human body [67, 97]. Indeed, enteric neurons play a vital regulating role in many gastro-intestinal functions such as the synchronization of activities of other intestinal cells, features of the gut motility, intestinal nutrient absorption, and cellular secretory functions i.e. mucous and gut hormones [67, 98, 99]. It is now well-known that the mammalian ENS undergoes remarkable developmental alterations post-birth and continues to go through modifications during the developmental stages of host life while maintaining a plasticity in terms of its pathophysiological functions $[90,98,100,101]$. Hence, it is reasonable to hypothesize that the enteric nervous system undergoes some degenerative changes in line with the changes in the host physiology, metabolism, microbiota and immune system during aging (Fig. 4). Several studies have pondered upon this association

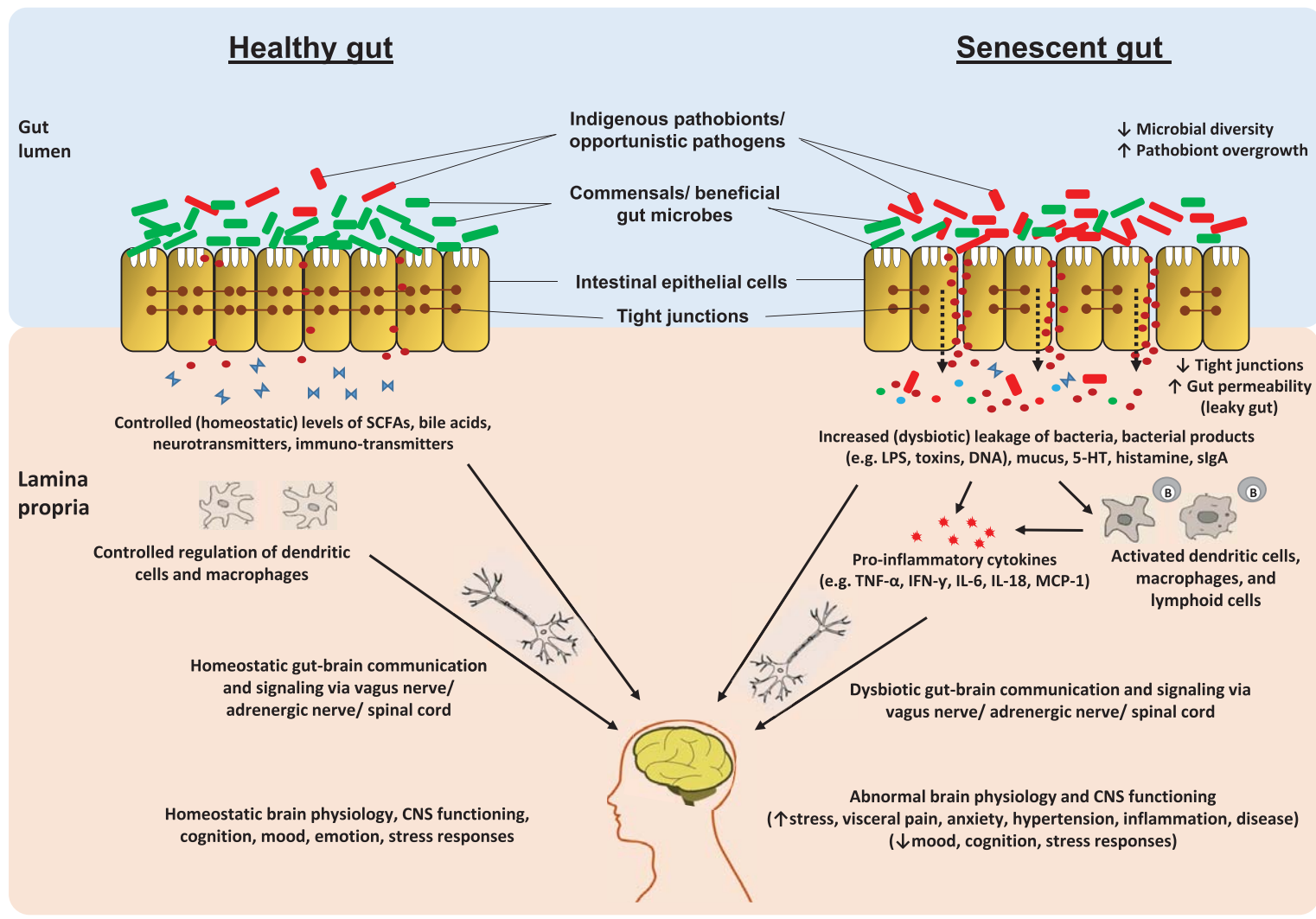

Fig. 4. Schematic illustration of putative pathway(s) by which aging-related alterations in gut microbiome and entero-neuro-endocrine system may affect brain health via deteriorated gut-brain communication signaling. In healthy adult host, the balanced gut microbiome configuration and intestinal barrier integrity help in maintaining balanced arrays of microbes, microbial by-products (e.g. short-chain fatty acids; SCFAs) and other entities such as neurotransmitters across the gut wall thereby maintaining a balanced enteric-immune and -inflammatory system through controlled proliferation of dendritic cells and macrophages which eventually helps in keeping the gut-brain communication and the functioning of central nervous system (CNS) under control. In old age, the altered gut microbiota diversity and weakened gut barrier integrity may perturb the microbial and biochemical environment across the intestinal epithelial cell lining via abnormal levels of SCFAs, lipopolysaccharide (LPS), secretory Immunoglobulin A (sIgA), histamins, serotonin (5-hydroxytryptamine; 5-HT), etc. thereby instigating an abnormal (hyper) inflammatory responses eventually affecting (disturbing) the gut-brain communication $[84,90,93,103,104,109,112$, $124,158]$. 
and found noticeable correlations between host aging and the features of the ENS; however, the results have been somewhat inconsistent and the precise mechanisms and cause-or-consequence issues remain to be deciphered completely.

For instance, a considerable decline in the numbers/function of myenteric neurons during aging has been reported [102, 103]; however, there are studies that observed no such degeneration of myenteric neurons with aging [104, 105]. Consequently, the question whether the ENS integrity/function undergoes senescence during host aging still remains debatable. Nevertheless, hostaging-related ENS-degeneration such as detection of dystrophic/degenerating nerve fibers [105, 106], altered morphology of enteric ganglia [107, 108], accumulated lipofuscin (yellow-brown pigment granules composed of lipid-containing residues of lysosomal digestion) in aged enteric neurons [108, 109 ], $\alpha$-synuclein-immunoreactive aggregates and hyper-phosphorylated Tau [110], and increased load of reactive oxygen species in myenteric neurons [111] has been reported in many animal studies. These evidences are clear indication of a correlation between host aging and senescence-like phenotypic changes in the ENS. The magnitude, however, of such hostsenescence-mediated impact on the decline/loss of enteric neuronal cells remains unclear and would undoubtedly involve quite a few underlying mechanisms. For instance, assuming that the ENS cells are highly distinct in terms of their morphological as well as functional characteristics, it is highly plausible that the susceptibility to aging-related impacts would differ greatly among different cell types. Also, since nerve cells are metabolically active, the burden of oxidative stress and free radical damage can also be speculated to be implicated directly or indirectly in the ENS-senescence [112]. Calcium dysregulation might be another underlying element in ENS-senescence, particularly given that the expression of calcium-binding proteins in the enteric nerve cells is found to be reduced in aged animals $[111,113]$. Alterations in the gene expression patterns for sodium channels in the ENS cells during the process of aging has also been recently reported [114]. Nevertheless, the features as well as the magnitude of these age-related changes in the characteristics and functions of the ENS cells at cellular as well as molecular level still remain to be confirmed and elucidated completely. Indeed, further investigation of these senescence-related outcomes in the ENS is indispensable and could provide novel insights into this intricate aging-and-gut association, and hence might also open new avenues and opportunities to develop novel therapies for the amelioration of various senescence-related neurogastroenterological maladies as well as to improve the quality of life during old age.

Also, given the proximity of enteric neurons with microbes dwelling in the gastrointestinal tract, it is apparently highly plausible that ENS is associated with (or perhaps even influenced/coordinated by) the gut microbiota. For instance, it has been suggested that early exposure to gut microbes is indispensable for the postnatal development of the ENS [115]. Furthermore, the initial colonization and homeostasis of glial cells in the intestinal mucosa is also known to be regulated by the indigenous intestinal microbiota [116]. Thence, especially given that the gut microbiome undergoes substantial changes during old-age [34], it is also not surprising to envisage that enteric neurons may be more susceptible to aging-related downfall and impairments than neurons in other bodily parts [103]. This might be attributed to altered microbiota equilibrium i.e. the reduced levels of beneficial/commensals and elevated levels of opportunistic pathobionts and also the consequent altered array of microbial metabolites around the gut lining [110] (Fig. 4). Such agingrelated alterations in the intestinal microbiome may instigate elevated intestinal inflammation which may eventually impact enteric neurons thereby leading to loss and/or impairments in various physiological and neurochemical functions of the ENS ultimately driving the ills of aging [117, 118]. Intriguingly, it has also been demonstrated that the ENS maintains and promotes intestinal health via modulating the gut microbiota community composition and that the microbiota composition would become altered or abnormal without a functional ENS [99]. It has also been known that hosts with perturbed intestinal motility can develop gut microbial dysbiosis and intestinal pathology [118-120], clearly hinting towards a profound role for the ENS in constraining gut microbiota composition and preventing the overgrowth of bacterial lineages that could otherwise drive diseases. Even though the clear-cut mechanisms still remain largely unclear, the intricate interaction between gut microbes, intestinal epithelial cells, mucosal immune system and the enteric neurons, particularly in contexts to the gut-brain axis and neuropathies in old-age, is now an area of great research and beginning to be interpreted [99, 121, 122] (Fig. 4). 


\section{Aging and the intestinal barrier and permeability: Is there a link?}

The intestinal barrier is the physical and functional separation between the environment and the host's interior and hence plays a crucial role in our health and disease by regulating various physiological process such as allowing selective passage of various essential substances and permitting the uptake/digestion of nutrients, while preventing the permeation of pathogens, toxins, antigens and other pro-inflammatory substances into the human body (Figs. 3 and 4) [85, 123, 124]. This gut barrier is composed mainly of a mucinous component secreted by intestinal epithelial cells, creating an intercellular junction (including tight junctions) layer that separates the systemic compartment from the external environment (Fig. 3A). Representing the longest interphase in our body with the exteriors, this intestinal epithelium (and gut barrier) is absolutely indispensable for regulating the gut homeostasis and maintaining overall host health. And hence, it is beyond doubt that any disturbance in the homeostasis of this barrier could lead to manifold harmful effects such as increased gut permeability (leaky gut), increased inflammatory triggers and outcomes, and perturbations in the intestinal and mucosal microbiota (dysbiosis), thereby instigating increased risk and incidence of various inflammatory and other gastrointestinal diseases such as irritable bowel syndrome (IBS), inflammatory bowel disease, celiac diseases, food allergies and intolerance andrheumatoid arthritis [125-133] (Fig. 3B).

Nevertheless, assuming that our gut microbiome and the ENS undergo considerable changes (gut dysbiosis) as we get older, it may also seem to be reasonable to speculate that the permeability of our intestinal barrier (leaky gut) is also increased as we age, especially given that the proneness to and incidences of - gastrointestinal disorders is also increased during old age [131, 134] (Figs. 3 and 4). Accordingly, several studies have attempted to explore and decode this connection. Several rodent studies have reported an altered smooth muscle contractility [135] and neural innervations of the musculature of the gastrointestinal tract [136] and an increased intestinal permeability to macromolecules $[137,138]$ in aged animals, together indicating some sort of age-related deterioration in the functions of the gastrointestinal barrier and integrity. Such deteriorations in the intestinal barrier function, such as (a) declined functions of Paneth cells and IgA-mediated mucosal immunity and (b) increased magnitude of pro-inflammatory cytokines and epithelial tightjunctions permeability, have been speculated to be implicated in increased vulnerability to infections in elderly humans $[84,123,131,139,140]$. However, the precise effects of host aging on the characteristics of the gut epithelial integrity and mucus layer (or vice-versa) still remain elusive and the key factors that increase the vulnerability to gastrointestinal ailments during old age remain largely unclear. One reason for this knowledge gap may be the slow, laborious and tedious involvement in studying the senescence-effects in aged animals. In this context, development of fast-aging animal models could prove to be facilitative and hence can be expected to incite future studies to explore this subject [141]. But it has to be validated to what degree the gut permeability, enteric neuron network, mucosal environment and the intestinal microbial ecosystem in such models correspond to those in normal/natural wild-type animals. Nevertheless, despite ever-mounting understanding of the importance of gut health in many aging-related diseases, it still remains ambiguous whether and how aging actually induce the negative impact on the intestinal mucosal integrity and permeability [131, 142, 143]. In addition, a number of studies have even suggested no or insignificant association between aging and intestinal barrier integrity [144, 145]; although it has been speculated that increased low-grade inflammation during old-age might increase the susceptibility of gut barrier perturbation and infections [145, 146]. For example a recent mice study demonstrated that aging-associated gut microbial dysbiosis instigates increase in intestinal permeability which leads to the leakage of microbial products in the circulation thereby triggering systemic inflammation and eventually contributing to the inflammatory state of the aged host [147]. Another interesting study also reported gut dysbiosis leading to the translocation of live gut bacteria into the blood of aged type- 2 diabetes patients, suggesting impaired gut permeability and increased predisposition to miscellaneous illnesses in such patients [126]. Nevertheless, given that an increased gut permeability can instigate numerous health complications and that the number of older people is rapidly increasing worldwide, further broader studies are awaited to answer these outstanding issues and to decipher the mechanisms underlying the triangle of gut dysbiosis, old-age and the proneness to (gut- and senescenceassociated) infections. 


\section{Microbiome derived metabolites in aging}

SCFAs (butyrate, propionate and acetate) have significant beneficial impacts on several features of the host metabolic and physiologic health such as maintaining a low luminal $\mathrm{pH}$, increasing the microbial biomass, fostering the growth of beneficial bacterial population, promoting and regulating mucus production, supporting gut barrier integrity and gut homeostasis, and shaping the peripheral metabolism. Among major SCFAs play a key role as an energy source for colonic epithelium (enterocytes) thereby contributing in $5-10 \%$ of total energy required by a healthy human body [148]. In addition, absorbed butyrate, the most-studied beneficial metabolite produced by the gut microbiota, may play protective role against colorectal cancer by inhibiting histone deacetylase which may otherwise stimulate the proliferation of colorectal cancer cells [149]. Propionate makes an important contribution in liver gluconeogenesis, helps in the regulation of cholesterol synthesis, and also plays a beneficial role against the development of cancers that might metastasize in the liver [150]. Acetate also acts as a substrate for liver lipogenesis and cholesterol synthesis, helps in the regulation of colonic blood flow and may also play a preventive role against liver carcinogenesis [151].

Given that the diet, drug exposures as well as the gut microbiome composition undergoes substantial changes during aging, the intestinal metabolic environment i.e. the levels of microbial metabolites viz. SCFAs also inevitably get affected with age. It is known that as compared to young subjects, old people have lower levels of SCFAs. For instance, a reduced colonic SCFA production has been found to be correlated with a lower fiber intake and antibiotic treatment during old age [152]. In addition, a rearrangement in the intestinal carriage of butyrateproducing bacteria has been reported in centenarians [83]. Such decline in intestinal SCFAs levels (possibly because of altered diet of the aged people) may favor intestinal populations of bacteria able to degrade mucin thereby increasing the possibility of entry of pathobionts into the intestinal mucosa [83]. Therefore, the reduced SCFAs levels in old age may increase susceptibility to inflammatory diseases like Crohn's disease and IBD. The age-related declination in SCFAs levels may also affect host immune and inflammatory health, which may eventually cause various gut-related diseases in old people. Reduced levels of butyrate have been found to be associated with a number of inflammatory intestinal diseases
[4, 83, 149, 152-154]. Given that the host metabolic health deteriorates during old age, it is highly plausible that this could partly be attributed to altered intestinal SCFAs levels. For instance, reduced levels of butyrate may instigate perturbations in the gut barrier integrity thereby increasing host's vulnerability to bacteremia and relevant illnesses [155]. Also, lower butyrate levels may impact insulin sensitivity and energy expenditure by affecting mitochondrial activity [156]. Reduced levels of propionate may also affect intestinal gluconeogenesis and gut-brain neural circuit via GPR-41 [157]. It has also been suggested that decline in SCFA-producing bacteria could modulate neuro-immune activation [158] which could underlie higher incidence of gastrointestinal perturbations linked with neurodegenerative disease including gut dysbiosis, diarrhea, constipation, obesity and diabetes [159]. In these contexts, dietary or relevant therapeutic interventions (e.g. using fiber-rich diets or indigestible-carbohydrates that promote SCFAs production through fermentation by gut bacteria) that restore/promote the microbiome in a way that the intestinal organic environment is also restored/promoted in terms of beneficial SCFAs might turn out to be effective for ameliorating the aging-related ailments, particularly those originating in the senescent gut.

\section{Probiotics, prebiotics and the healthy aging: In pursuit of longevity}

Owing to recent revelation of the association between aging and the intestinal microbiota, it is not surprising that the gut microbial ecosystem is receiving considerable attention as a potential target for developing novel strategies for healthier aging and wellbeing of elderly. However, the concept of manipulating gut microbiota for healthy aging can be dated back to as early as 20th century when Nobel laureate Elie Metchnikoff hypothesized that age-related illnesses are primarily the consequences of reactive phagocytes impairing healthy tissues as a response to autotoxins in the gut, and that restoring gut microflora by regularly ingesting yogurt could promote healthier aging [160]. While a causal relationship has not yet been determined, the available evidences on the associations between gut microbiota, nutrition and systemic inflammation suggest that dietary interventions for positively modulating the microbiota composition and diversity could help in promoting the healthier aging and longevity $[34,161]$. In this 
context, probiotics and prebiotics might prove to be promising candidates for developing dietary interventions for promotion and maintenance of healthy gut microbiota.

Probiotics are "live microorganisms that, when administered in adequate amounts, confer a health benefit on the host"; [196]. Prebiotics are "nondigestible food ingredients which selectively stimulate the growth and/or activity of one or a limited number of bacteria in the colon' [162]. Interestingly, the overall target of both, probiotics and prebiotics is similar i.e., restoring and/or maintaining the homeostasis of gut microbial ecosystem, which can be particularly crucial during old age [34, 152]. Since prebiotics are 'favorite' foods for probiotics, combining them as "synbiotics" for preventive as well as therapeutic health effects could be envisaged for better gut and overall health [46, 163]. Fermentation of prebiotics by probiotics, mainly bifidobacteria and lactobacilli, also increases the intestinal levels of SCFAs especially butyrate which have been shown to confer immune-modulating and anti-inflammatory effects [164]. These effects could be particularly important for elderly people, because they are already going through immune-senescence and are at increased risk of developing miscellaneous infections and illnesses [165, 166].

Most of the probiotic products are based on one or more strains of lactobacilli and bifidobacteria, whereas prebiotics are generally comprised of complex carbohydrates such as inulin, galactooligosaccharides, fructo-oligosaccharides and others [167]. Thus, it is not surprising that probiotics and prebiotics are observed to increase the numbers of bifidobacteria and lactobacilli in the intestine, thereby positively modifying the gut microbiota composition in elderly [168, 169, 170] and eventually to some extent aiding in the prevention of senescence-related diseases such as $C$. difficile-associated diarrhea, constipation, and common respiratory and gastrointestinal infections [171-174]. These preventative effects against the risk of infections have also been attributed partly to the immune-modulatory and anti-inflammatory activities of probiotics, for e.g. increased NK (natural killer) cell activity, increased phagocytosis, which may underlie the amelioration of immune-aging [165, 175-177]. However, as reviewed elegantly by Duncan and Flint [178], the available body of evidence is still too limited and inconsistent to interpret any substantial conclusion about the efficacy and working mechanisms of probiotics and prebiotics in the prevention of old-age related illnesses and immune-senescence. Nevertheless, it has been hypothesized that probiotic strains isolated from healthy elderly subjects or centenarians could be potential candidates for developing probiotic-based therapies intended for healthier aging [179-181]. Thus, studies are expected in future to elucidate the ameliorative effects and underlying mechanisms of such probiotic strains in the elderly.

In line with probiotics, many prebiotics have also been explored in human studies, mainly in context to their positive effects on the modification of human gut microbiota, i.e. promoting beneficial microbes and suppressing harmful bugs $[167,178,182]$. However, studies in elderly subjects have focused mainly on inulin and oligosaccharides [183, 184]. Besides modifying the gut microbiota, prebiotics have also been observed to have anti-inflammatory effect and positively modulate the immune system in elderly people [164]. These effects have also been speculated to aid in relieving the symptoms of irritable bowel syndrome [185]. Besides oligosaccharides, several other prebiotic compounds such as resistant starch, maize fiber, and polydextrose have also been found to positively modulate the gut microbiota and increase SCFA concentrations [186-188]. Interestingly, animal studies have also hinted at possible preventive effects of prebiotics such as resistant starch against colon cancer [189]. While these effects are not yet fully established and translated through to the real-world situations, these preliminary observations do hint towards their possible potential in improving the gut environment and lowering the incidences of senescent illnesses [178]. Nevertheless, owing to the facts that (a) the gut microbiota and intestinal environment significantly varies between individuals, (b) the effects of probiotics are highly strain-specific and host-specific, (c) the effects of prebiotics on microbiota composition are compound-specific and host-specific, it is exceedingly challenging to elucidate and validate the precise health effects and underlying mechanisms, and hence a lot more research is still awaited to substantiate the beneficial effects of probiotics and prebiotics in healthy as well as in diseased subjects.

While the research on exploring microbiota-based preventive or therapeutic interventions has focus hitherto mainly on probiotic and prebiotics, a novel approach called fecal microbiome transplantation (FMT) has gained considerable attention in recent years. In essence, FMT is the transfer of a small aliquot of healthy donor's feces into the intestinal tract of recipient or the patient. In fact, this approach 
has already shown promising results against recurrent C. difficile colitis, particularly in restoring the intestinal homeostasis and preventing the recurrence of $C$. difficile infection [5, 190-192]. While research is still in infancy regarding the safety, efficacy and validity of FMT, there are positive speculations regarding its potential use in other gut-related ailments i.e. inflammatory bowel disease, irritable bowel syndrome, obesity, type 2 diabetes, metabolic syndrome and colorectal cancer [190, 193-195]. Of course, one of the main challenges would be the standardization of the technique so as to rule out any possible risk of infection. But considering the available evidences and speculations, a day may be envisaged in future when a standardized cocktail of healthy bugs obtained from healthy centenarians' feces would be available to be used for promoting healthy aging and longevity of the elderly. Nevertheless, future studies are awaited to evaluate and validate the ultimate efficacy of this approach while diminishing as much as possible the likelihood of side-effects.

\section{Conclusion and future perspectives}

Thanks to the revolutionary advent of highthroughput sequencing and metagenomic tools, we are now beginning to reveal the 'healthy' or 'ideal' gut microbiota configuration and understand the complexities and functionalities of gut microbes in health and disease. Considering the remarkably enthusiastic pace with which research on the elements of gut microbiota is speeding on, it can be anticipated that we will soon be able to know 'which' gut microbe is doing 'what' and 'why' and 'how'. And then, we will possibly be able to predict the risk of developing gut dysbiosis and related illnesses much before it happens and timely repair the microbiota to ensure a resilient and healthy microbiota for healthy aging. However, still there are several outstanding questions about the gut microbiome and aging i.e. (i) is aging a disease? (ii) if so, is gut dysbiosis an underlying pathophysiological factor or just a consequence of senescence? (iii) Can we delay aging by microbiome modulation? if so, then how and at what stage do we consider modulating the microbiota? (iv) can gut-targeted therapies such as probiotics and prebiotics help in ameliorating aging? (v) is declined cognitive function in old age instigated by or linked with the dysbiosis of gut microbiota, gut barrier integrity, ENS, or the gut-brain axis? and, (vi) can (and how) nutritional modifications aid in improving aging-related health issues? Indeed, given the mounting evidence that the gut microbiome plays a fundamental role in numerous aspects of our health and disease, it can be easily envisioned that novel personalized nutritional and therapeutic approaches targeting the intestinal microbiota such as probiotics, prebiotics, nutraceuticals, functional foods, and fecal microbiota transplantation may offer potential avenues for better health and wellbeing with a particular relevance for our senior comrades. Owing to the fact that an aging population is now a general characteristic of not only developed but also many developing countries and entails significant healthcare resources, developing novel and effective strategies for promotion and maintenance of healthier microbiota can be expected to be valuable not only for healthier and happier aging but for national economic systems as well.

\section{Acknowledgments}

We are thankful for the intramural funding support from Wake Forest School of Medicine, as well as in part by NIH grants R01AG18915 and P30AG12232, and by the Kermit Glenn Phillips II Endowed Chair in Cardiovascular Medicine.

\section{Conflicts of interest}

The authors declare no conflict of interest.

\section{References}

[1] Kenyon CJ. The genetics of aging. Nature. 2010;464(7288):504-12.

[2] Lopez-Otin C, Blasco MA, Partridge L, Serrano M, Kroemer G. The hallmarks of aging. Cell. 2013;153(6): 1194-217.

[3] Cevenini E, Caruso C, Candore G, Capri M, Nuzzo D, Duro G, Rizzo C, Colonna-Romano G, Lio D, Di Carlo D, Palmas MG, Scurti M, Pini E, Franceschi C, Vasto S. Age-related inflammation: The contribution of different organs, tissues and systems. How to face it for therapeutic approaches. Curr Pharm. 2010;16(6):609-18.

[4] Biagi E, Candela M, Fairweather-Tait S, Franceschi C, Brigidi P. Aging of the human metaorganism: The microbial counterpart. Age (Dordr). 2012;34(1):247-67.

[5] Keller JM, Surawicz CM. Clostridium difficile infection in the elderly. Clin Geriatr Med. 2014;30(1):79-93.

[6] Zapata HJ, Quagliarello VJ. The microbiota and microbiome in aging: Potential implications in health and age-related diseases. J Am Geriatr Soc. 2015;63(4):776-81.

[7] Buford TW. (Dis) Trust your gut: The gut microbiome in age-related inflammation, health, and disease. Microbiome. 2017;5(80):1-11. 
[8] Han B, Sivaramakrishnan P, Lin CCJ, Neve IAA, He J, Tay LWR, Sowa JN, Sizovs A, Du G, Wang J, Herman C, Wang MC. Microbial genetic composition tunes host longevity. Cell. 2017;169(13):1249-62.

[9] Sleator RD. The human superorganism of microbes and men. Med Hypotheses. 2010;74(2):214-5.

[10] Moskalev AA, Shaposhnikov MV, Plyusnina EN, Zhavoronkov A, Budovsky A, Yanai H, Fraifeld VE. The role of DNA damage and repair in aging through the prism of Koch-like criteria. Aging Res Rev. 2013;12(2): 661-84.

[11] Jimenez E, Fernandez L, Marin ML, Martin R, Odriozola JM, Nueno-Palop C, Narbad A, Olivares M, Xaus $\mathrm{J}$, Rodriguez JM. Isolation of commensal bacteria from umbilical cord blood of healthy neonates born by caesarean section. Curr Microbiol. 2005;51(4):270-4.

[12] Oh KJ, Lee SE, Jung H, Kim G, Romero R, Yoon BH. Detection of urea plasmas by the polymerase chain reaction in the amniotic fluid of patients with cervical insufficiency. J Perinat Med. 2010;38:261-8.

[13] Aagaard K, Ma J, Antony KM, Ganu R, Petrosino J, Versalovic J. The placenta harbors a unique microbiome. Sci Transl Med. 2014;6(237):237-65.

[14] Collado MC, Rautava S, Aakko J, Isolauri E, Salminen S. Human gut colonisation may be initiated in utero by distinct microbial communities in the placenta and amniotic fluid. Sci Rep. 2016;6(1):23129.

[15] Nagpal R, Tsuji H, Takahashi T, Kawashima K, Nagata S, Nomoto K, Yamashiro Y. Sensitive quantitative analysis of the meconium bacterial microbiota in healthy term infants born vaginally or by cesarean section. Front Microbiol. 2016a;7:1997.

[16] Nagpal R, Kurakawa T, Tsuji H, Takahashi T, Kawashima K, Nagata S, Nomoto K, Yamashiro Y. Dynamics of the gut Bifidobacterium microbiota during the first three years of life: A quantitative assessment. Sci Rep. 2017a;7(1): 10097.

[17] Nagpal R, Tsuji H, Takahashi T, Kawashima K, Nagata S, Nomoto K, Yamashiro Y. Gut dysbiosis following $\mathrm{C}$-section instigates higher colonization of $\alpha$-toxigenic and enterotoxigenic $C$. perfringens in infants. Benef Microbes. 2017b;8(3):353-65.

[18] Nagpal R, Tsuji H, Takahashi T, Nomoto K, Kawashima K, Nagata S, Yamashiro Y. Ontogenesis of the gut microbiota development in healthy fullterm vaginally-born breast-fed infants over the first 3 years of life: A quantitative bird's-eye view. Front Microbiol. 2017c.8:1388.

[19] Palmer C, Bik EM, DiGiulio DB, Relman DA, Brown PO. Development of the human infant intestinal microbiota. PLoS Biol. 2007;5(7):e177.

[20] Tsuji H, Oozeer R, Matsuda K, Matsuki T, Ohta T, Nomoto K, Tanaka R, Kawashima M, Kawashima K, Nagata S, Yamashiro Y. Molecular monitoring of the development of intestinal microbiota in Japanese infants. Benef Microbes. 2012;3(2):113-25.

[21] Backhed F, Roswall J, Peng Y, Feng Q, Jia H, KovatchevaDatchary P, Li Y, Xia Y, Xie H, Zhong H, Khan MT, Zhang J, Li J, Xiao L, Al-Aama J, Zhang D, Lee YS, Kotowska D, Colding C, Tremaroli V, Yin Y, Bergman S, Xu X, Madsen L, Kristiansen K, Dahlgren J, Wang J. Dynamics and stabilization of the human gut microbiome during the first year of life. Cell Host Microbe. 2015;17(6):852.
[22] Bokulich NA, Chung J, Battaglia T, Henderson N, Jay M, Li H, D Lieber A, Wu F, Perez-Perez GI, Chen Y, Schweizer W, Zheng X, Contreras M, Dominguez-Bello MG, Blaser MJ. Antibiotics, birth mode, and diet shape microbiome maturation during early life. Sci Transl Med. 2016;8(343): 343-82.

[23] Odamaki T, Kato K, Sugahara H, Hashikura N, Takahashi S, Xiao JZ, Abe F, Osawa R. Age-related changes in gut microbiota composition from newborn to centenarian: A cross-sectional study. BMC Microbiol. 2016;16(1):90.

[24] Penders J, Thijs C, Vink C, Stelma FF, Snijders B, Kummeling I, van den Brandt PA, Stobberingh EE. Factors influencing the composition of the intestinal microbiota in early infancy. Pediatrics. 2006;118(2):511-21.

[25] Dominguez-Bello MG, Costello EK, Contreras M, Magrisd M, Hidalgod G, Fierere N, Knightb R. Delivery mode shapes the acquisition and structure of the initial microbiota across multiple body habitats in newborns. Proc Natl Acad Sci USA. 2010;107(26):11971-5.

[26] Nagpal R, Yamashiro Y. Early life gut microbial composition. J Ped Biochem. 2015;5(2):41-50.

[27] Gronlund MM, Lehtonen OP, Eerola E, Kero P. Fecal microflora in healthy infants born by different methods of delivery: Permanent changes in intestinal flora after cesarean delivery. J Ped Gastroenterol Nutr. 1999;28(1): 19-25.

[28] Favier CF, Vaughan EE, De Vos WM, Akkermans AD. Molecular monitoring of succession of bacterial communities in human neonates. Appl Environ Microbiol. 2002;68(1):219-26.

[29] De Filippo C, Cavalieri D, Di Paola M, Ramazzottic M, Baptiste Poulletd J, Massartd S, Collinib S, Pieraccinie G, Lionetti P. Impact of diet in shaping gut microbiota revealed by a comparative study in children from Europe and rural Africa. Proc Natl Acad Sci USA. 2010;107(33):14691-6.

[30] David LA, Maurice CF, Carmody RN, Gootenberg DB, Button JE, Wolfe BE, Ling AV, Devlin AS, Varma Y, Fischbach MA, Biddinger SB, Dutton RJ, Turnbaugh PJ. Diet rapidly and reproducibly alters the human gut microbiome. Nature. 2014;505(7484):559-63.

[31] Bartosch S, Fite A, Macfarlane GT, McMurdo M. E. T. Characterization of bacterial communities in feces from healthy elderly volunteers and hospitalized elderly patients by using real-time PCR and effects of antibiotic treatment on the fecal microbiota. Appl Environ Microbiol. 2004;70(6):3575-81.

[32] Claesson MJ, Cusack S, O'Sullivan O, Greene-Diniz R, de Weerd H, Flannery E, Marchesi JR, Falush D, Dinan T, Fitzgerald G, Stanton C, van Sinderen D, O'Connor M, Harnedy N, O'Connor K, Henry C, O'Mahony D, Fitzgerald AP, Shanahan F, Twomey C, Hill C, Ross RP, O'Toole PW. Composition, variability, and temporal stability of the intestinal microbiota of the elderly. Proc Natl Acad Sci USA. 2011;15(108):4586-91.

[33] O'Toole PW, Jeffery IB. Gut microbiota and aging. Science. 2015;350(6265):1214-5.

[34] Claesson MJ, Jeffery IB, Conde S, Power SE, O'Connor EM, Cusack S, Harris HMB, Coakley M, Lakshminarayanan B, O'Sullivan O,Gerald F. Fitzgerald, Deane J, O'Connor M, Harnedy N, O'Connor K, O'Mahony D, Sinderen Dv, Wallace M, Brennan L, Stanton C, Marchesi JR, Fitzgerald AP, Shanahan F, Hill C, Ross RP, O'Toole PW. 
Gut microbiota composition correlates with diet and health in the elderly. Nature. 2012;488(7410):178-84.

[35] Collino S, Montoliu I, Scherer M, Mari D, Salvioli S, Bucci L, Ostan R, Monti D, Biagi E, Brigidi P, Franceschi C, Rezzi $\mathrm{S}$. Metabolic signatures of extreme longevity in northern Italian centenarians reveal a complex remodeling of lipids, amino acids, and gut microbiota metabolism. PLoS One. 2013;8(8): e56564.

[36] Mitchell EL, Davis AT, Brass K, Dendinger M, Barner R, Gharaibeh R, Fodor AA, Kavanagh K. Reduced intestinal motility, mucosal barrier function, and inflammation in aged monkeys. J Nutr Health Aging. 2017;21(4):354-61.

[37] Gavini F, Cayuela C, Antoine J-M, Lecoq C, Lefebvre B, Membre JM, Neut C. Differences in the distribution of bifidobacterial and enterobacterial species in human faecal microflora of three different (children, adults, elderly) age groups. Microb Ecol Health Dis. 2001;13(1): 40-5.

[38] He F, Ouwehand AC, Isolauri E, Hosoda M, Benno Y, Seppo $\mathrm{S}$. Differences in composition and mucosal adhesion of bifidobacteria isolated from healthy adults and healthy seniors. Curr Microbiol. 2001;43(5):351-4.

[39] Hopkins MJ, Macfarlane GT. Changes in predominant bacterial populations in human faeces with age and with Clostridium difficile infection. J Med Microbiol. 2002;51(5):448-54.

[40] Makivuokko H, Tiihonen K, Tynkkynen S, Paulin L, Rautonen N. The effect of age and non-steroidal antiinflammatory drugs on human intestinal microbiota composition. Br J Nutr. 2010;103(2):227-34.

[41] Rea MC, O'Sullivan O, Shanahan F, O'Toole PW, Stanton C, Ross RP, Hill C. Clostridium difficile carriage in elderly subjects and associated changes in the intestinal microbiota. J Clin Microbiol. 2012;50(3):867-75.

[42] Benno Y, Endo K, Mizutani T, Namba Y, Komori T, Mitsuoka T. Comparison of fecal microflora of elderly persons in rural and urban areas of Japan. Appl Environ Microbiol. 1989;55(5):1100-5.

[43] Hayashi H, Sakamoto M, Kitahara M, Benno Y. Molecular analysis of fecal microbiota in elderly individuals using 16S rDNA library and T-RFLP. Microbiol Immunol. 2003;47(8):557-70.

[44] Mueller S, Saunier K, Hanisch C, Norin E, Alm L, Midtvedt T, Cresci A, Silvi S, Orpianesi C, Verdenelli MC, Clavel T, Koebnick C, Zunft HJ, Doré J, Blaut M. Differences in fecal microbiota in different European study populations in relation to age, gender, and country: A cross-sectional study. Appl Environ Microbiol. 2006;72(2):1027-33.

[45] Zwielehner J, Liszt K, Handschur M, Lassl C, Lapin A, Haslberger AG. Combined PCR-DGGE fingerprinting and quantitative-PCR indicates shifts in fecal population sizes and diversity of Bacteroides, bifidobacteria and Clostridium cluster IV in institutionalized elderly. Exp Gerontol. 2009;44(6-7):440-6.

[46] Biagi E, Candela M, Turroni S, Garagnani P, Franceschi C, Brigidi P. Aging and gut microbes: Perspectives for health maintenance and longevity. Pharmacol Res. 2013;69(1):1120.

[47] Turnbaugh PJ, Ley RE, Mahowald MA, Magrini V, Mardis ER, Gordon JI. An obesity-associated gut microbiome with increased capacity for energy harvest. Nature. 2006;444(7122):1027-31.
[48] Rampelli S, Candela M, Turroni S, Biagi E, Collino S, Franceschi C, O’Toole PW, Brigidi P. Functional metagenomic profiling of intestinal microbiome in extreme ageing. Aging 2013;5(12):902-12.

[49] Ursell LK, Haiser HJ, Van Treuren W, Garg N, Reddivari L, Vanamala J, Dorrestein PC, Turnbaugh PJ, Knight R. The intestinal metabolome: An intersection between microbiota and host. Gastroenterology. 2014;146(6):1470-6.

[50] Rios-Covian D, Ruas-Madiedo P, Margolles A, Gueimonde M, de Los Reyes-Gavilan CG, Salazar N. Intestinal short chain fatty acids and their link with diet and human health. Front Microbiol. 2016;7:185.

[51] Maslowski KM, Vieira AT, Ng A, Kranich J, Sierro F, Yu D, Schilter HC, Rolph MS, Mackay F, Artis D, Xavier RJ, Teixeira MM, Mackay CR. Regulation of inflammatory responses by gut microbiota and chemoattractant receptor GPR43. Nature. 2009;461(7268):1282-6.

[52] Wikoff WR, Anfora AT, Liu J, Schultz PG, Lesley SA, Peters EC, Siuzdak G. Metabolomics analysis reveals large effects of gut microflora on mammalian blood metabolites. Proc Natl Acad Sci USA. 2009;106(10):3698-703.

[53] Nicholson JK, Holmes E, Kinross J, Burcelin R, Gibson G, Jia W, Pettersson S. Host-gut microbiota metabolic interactions. Science. 2012;336(6086):1262-7.

[54] Org E, Blum Y, Kasela S, Mehrabian M, Kuusisto J, Kangas AJ, Soininen P, Wang Z, Ala-Korpela M, Hazen SL, Laakso $\mathrm{M}$, Lusis AJ. Relationships between gut microbiota, plasma metabolites, and metabolic syndrome traits in the METSIM cohort. Genome Biol. 2017;18(1):70.

[55] Romero R, Erez O, Hüttemann M, Maymon E, Panaitescu B, Conde-Agudelo A, Pacora P, Yoon BH, Grossman LI. Metformin, the aspirin of the 21st century: Its role in gestational diabetes mellitus, prevention of preeclampsia and cancer, and the promotion of longevity. Am J Obstet Gynecol. 2017;217(3):282-302.

[56] Cabreiro F, Au C, Leung KY, Vergara-Irigaray N, Cocheme HM, Noori T, Weinkove D, Schuster E, Greene NDE, Gems D. Metformin retards aging in C. elegans by altering microbial folate and methionine metabolism. Cell. 2013;153(1):228-39.

[57] Virk B, Correia G, Dixon DP, Feyst I, Jia J, Oberleitner N, Briggs Z, Hodge E, Edwards R, Ward J, Gems D, Weinkove D. Excessive folate synthesis limits lifespan in the C. elegans: E. coli aging model. BMC Biol. 2012; 10:67.

[58] Martin-Montalvo A, Mercken EM, Mitchell SJ, Palacios HH, Mote PL, Scheibye-Knudsen M, Gomes AP, Ward TM, Minor RK, Blouin MJ, Schwab M, Pollak M, Zhang Y, Yu Y, Becker KG, Bohr VA, Ingram DK, Sinclair DA, Wolf NS, Spindler SR, Bernier M, de Cabo R. Metformin improves health-span and lifespan in mice. Nat Commun. 2013;4:2192.

[59] Espinoza S, Walston JD. Frailty in older adults: Insights and interventions. Cleve Clin J Med. 2005;72(12):1105-12.

[60] Myers JS. Factors associated with changing cognitive function in older adults: Implications for nursing rehabilitation. Rehabil Nurs. 2008;33(3):117-23.

[61] Yamada M, Arai H, Yoshimura K, Kajiwara Y, Sonoda T, Nishiguchi S, Aoyama T. Nutritional supplementation during resistance training improved skeletal muscle mass in community-dwelling frail older adults. J Frailty Aging 2012;1(2):64-70. 
[62] Lakshminarayanan B, Stanton C, O’Toole PW, Ross RP. Compositional dynamics of the human intestinal microbiota with aging: Implications for health. J Nutr Health Aging. 2014;18(9):773-86.

[63] Rakoff-Nahoum S, Paglino J, Eslami-Varzaneh F, Edberg S, Medzhitov R. Recognition of commensal microflora by toll-like receptors is required for intestinal homeostasis. Cell. 2004;118(2):229-41.

[64] Belkaid Y, Hand TW. Role of the microbiota in immunity and inflammation. Cell. 2014;157(1):121-41.

[65] Abt MC, Osborne LC, Monticelli LA, Doering TA, Alenghat T, Sonnenberg GF, Paley MA, Antenus M, Williams KL, Erikson J, Wherry EJ, Artis D. Commensal bacteria calibrate the activation threshold of innate antiviral immunity. Immunity. 2012;37(1):158-70.

[66] Belkaid Y, Naik S. Compartmentalized and systemic control of tissue immunity by commensals. Nat Immunol. 2013;14(7):646-53.

[67] Yoo BB, Mazmanian SK. The enteric network: Interactions between the immune and nervous systems of the gut. Immunity. 2017;46(6):910-26.

[68] Bouskra D, Brezillon C, Berard M, Werts C, Varona R, Boneca IG, Eberl G. Lymphoid tissue genesis induced by commensals through NOD1 regulates intestinal homeostasis. Nature. 2008;456(7221):507-10.

[69] Mazmanian SK, Liu CH, Tzianabos AO, Kasper DL. An immunomodulatory molecule of symbiotic bacteria directs maturation of the host immune system. Cell. 2005;122(1):107-18.

[70] Ivanov II, Fruto LR, Manel L, Yoshinaga K, Rifkin DB, Sartor RB, Finlay BB, Littman DR. Specific microbiota direct the differentiation of IL-17-producing T-helper cells in the mucosa of the small intestine. Cell Host Microbe. 2008;4(4):337-49.

[71] Christensen HR, Frokiar H, Petska JJ. Lactobacilli differentially modulate expression of cytokines and maturation surface markers in murine dendritic cells. J Immunol. 2002;168(1):171-8.

[72] Kelsall BL, Leon F. Involvement of intestinal dendritic cells in oral tolerance, immunity to pathogens, and inflammatory bowel disease. Immunol Rev. 2005;20(1):132-48.

[73] Maffei VJ, Kim S, Blanchard E, Luo M, Jazwinski SM, Taylor CM, Welsh DA. Biological aging and the human gut microbiota. J Gerontol A Biol Sci Med Sci. 2017. doi: 10.1093/gerona/glx042

[74] Jackson MA, Jeffery IB, Beaumont M, Bell JT, Clark AG, Ley RE, O'Toole PW, Spector TD, Steves CJ. Signatures of early frailty in the gut microbiota. Genome Med. 2016;8(1):8.

[75] Jeffery IB, Lynch DB, O'Toole PW. Composition and temporal stability of the gut microbiota in older persons. ISME J. 2016;10(1):170-82.

[76] Kumar A, Wu H, Collier-Hyams LS, Hansen JM, Li T, Yamoah K, Pan ZQ, Jones DP, Neish AS. Commensal bacteria modulate cullin-dependent signaling via generation of reactive oxygen species. EMBO J. 2007;26(21):4457-66.

[77] Kelly CP, Pothoulakis C, LaMont JT. Clostridium difficile Colitis. N Engl J Med. 1994;330(4):257-62.

[78] Pamer EG. Immune responses to commensal and environmental microbes. Nat Immunol. 2007;8(11):1173-8.

[79] Sansonetti PJ. To be or not to be a pathogen: That is the mucosally relevant question. Mucosal Immunol. 2011;4(1):8-14
[80] Macpherson AJ, Harris NL. Interactions between commensal intestinal bacteria and the immune system. Nat Rev Immunol. 2004;4(6):478-85.

[81] Franceschi C, Bonafe M, Valensin S, Olivieri F, De Luca M, Ottaviani E, De Benedictis G. Inflamm-aging. An evolutionary perspective on immunosenescence. Ann N Y Acad Sci. 2000;908:244-54.

[82] Ouwehand AC, Bergsma N, Parhiala R, Lahtinen S, Gueimonde M, Finne-Soveri H, Strandberg T, Pitkala K, Salminen S. Bifidobacterium microbiota and parameters of immune function in elderly subjects. FEMS Immunol Med Microbiol. 2008;53(1):18-25.

[83] Biagi E, Nylund L, Candela M, Ostan R, Bucci L, Pini E, Nikkïla J, Monti D, Satokari R, Franceschi C, Brigidi P, De Vos W. Through aging, and beyond: Gut microbiota and inflammatory status in seniors and centenarians. PloS One. 2010;5(5):e10667.

[84] Man AL, Gicheva N, Nicoletti C. The impact of aging on the intestinal epithelial barrier and immune system. Cell Immunol. 2014;289(1-2):112-8.

[85] Nagpal R, Yadav H. Bacterial translocation from the gut to the distant organs: An overview. Ann Nutr Metab. 2017;71(1):11-6.

[86] Schwab L, Goroncy L, Palaniyandi S, Gautam S, Triantafyllopoulou A, Mocsai A, Reichardt W, Karlsson FJ, Radhakrishnan SV, Hanke K, Schmitt-Graeff A, Freudenberg M, von Loewenich FD, Wolf P, Leonhardt F, Baxan N, Pfeifer D, Schmah O, Schönle A, Martin SF, Mertelsmann R, Duyster J, Finke J, Prinz M, Henneke P, Häcker H, Hildebrandt GC, Häcker G, Zeiser R. Neutrophil granulocytes recruited upon translocation of intestinal bacteria enhance graft-versus-host disease via tissue damage. Nat Med. 2014;20(6):648-54.

[87] Schnabl B, Brenner DA. Interactions between the intestinal microbiome and liver diseases. Gastroenterology. 2014;146(6):1513-24.

[88] Nagpal R, Kumar M, Yadav AK, Hemalatha R, Yadav $\mathrm{H}$, Marotta F, Yamashiro Y. Gut microbiota in health and disease: An overview focused on metabolic inflammation. Benef Microbes. 2016b;7(2):181-94.

[89] Burcelin R, Serino M, Chabo C, Blasco-Baque V, Amar J. Gut microbiota and diabetes: From pathogenesis to therapeutic perspective. Acta Diabetol. 2011;48(4):257-73.

[90] Collins SM, Surette M, Bercik P. The interplay between the intestinal microbiota and the brain. Nat Rev Microbiol. 2012;10(11):735-42.

[91] Luna RA, Foster JA. Gut brain axis: Diet microbiota interactions and implications for modulation of anxiety and depression. Curr Opin Biotechnol. 2015;32:35-41.

[92] Vaiserman AM, Koliada AK, Marotta F. Gut microbiota: A player in aging and a target for anti-aging intervention. Ageing Res Rev. 2017;35:36-45.

[93] Rehman T. Role of the gut microbiota in age-related chronic inflammation. Endocr Metab Immune Disord Drug Targets. 2012;12(4):361-7.

[94] Friedland RP. Mechanisms of molecular mimicry involving the microbiota in neurodegeneration. J Alzheimers Dis. 2015;45(2):349-62.

[95] Sanduzzi Zamparelli M, Compare D, Coccoli P, Rocco A, Nardone OM, Marrone G, Gasbarrini A, Grieco A, Nardone G, Miele L. The metabolic role of gut microbiota in the development of nonalcoholic fatty liver disease and cardiovascular disease. Int J Mol Sci. 2016;17(8):e1225. 
[96] Furness JB. The enteric nervous system and neurogastroenterology. Nat Rev Gastroenterol Hepatol. 2012;9(5): 286-94.

[97] Paun A, Danska JS. Modulation of type 1 and type 2 diabetes risk by the intestinal microbiome Pediatr. Diabetes. 2016;17(7):469-77.

[98] Saffrey M, Jill. Aging of the mammalian gastrointestinal tract: A complex organ system. AGE. 2014;36(3):1019-32.

[99] Rolig AS, Mittge EK, Ganz J, Troll JV, Melancon E, Wiles TJ, Alligood K, Stephens WZ, Eisen JS, Guillemin $\mathrm{K}$. The enteric nervous system promotes intestinal health by constraining microbiota composition. PLoS Biol. 2017;15(2):e2000689.

[100] De Vries P, Soret R, Suply E, Heloury Y., Neunlist M. Postnatal development of myenteric neuro-chemical phenotype and impact on neuromuscular transmission in the rat colon. Am J Physiol Gastrointest Liver Physiol. 2010;299(2):G539-47.

[101] Foong JP, Nguyen TV, Furness JB, Bornstein JC, Young HM. Myenteric neurons of the mouse small intestine undergo significant electrophysiological and morphological changes during postnatal development. J Physiol. 2012;590(10):2375-90.

[102] Cowen T, Johnson RJR, Soubeyre V, Santer RM. Restricted diet rescues rat enteric motor neurons from age related cell death. Gut. 2000;47(5):653-60.

[103] Saffrey MJ. Cellular changes in the enteric nervous system during aging. Dev Biol. 2013;382(1):344-55.

[104] Van Ginneken C, Schafer KH, Van Dam D, Huygelen V, De Deyn PP. Morphological changes in the enteric nervous system of aging and APP23 transgenic mice. Brain Res. 2011;1378:43-53.

[105] Gamage PPK, Ranson RN, Patel BA, Yeoman MS, Saffrey MJ. Myenteric neuron numbers are maintained in aging mouse distal colon. Neurogastroenterol Motil. 2013;25(7):e495-505.

[106] Phillips RJ, Kieffer EJ, Powley TL. Aging of the myenteric plexus: Neuronal loss is specific to cholinergic neurons. Auton Neurosci. 2003;106(2):69-83.

[107] Hanani M, Fellig Y, Udassin R, Freund HR. Age-related changes in the morphology of the myenteric plexus of the human colon. Auton Neurosci. 2004;113(1-2): 71-8.

[108] Abalo R, Vera G, Rivera AJ, Martin MI. Age-related changes in the gastrointestinal tract: A functional and immune histochemical study in guinea-pig ileum. Life Sci. 2007;80(26):2436-45.

[109] Phillips RJ, Kieffer EJ, Powley TL. Loss of glia and neurons in the myenteric plexus of the aged Fischer 344 rat. Anat Embryol. 2004;209(1):19-30.

[110] Phillips RJ, Walter GC, Ringer BE, Higgs KM, Powley TL. Alpha-synuclein immune-positive aggregates in the myenteric plexus of the aging Fischer 344 rat. Exp Neurol. 2009;220(1):109-19.

[111] Thrasivoulou C, Soubeyre V, Ridha H, Giuliani D, Giaroni C, Michael GJ, Saffrey MJ, Cowen T. Reactive oxygen species, dietary restriction and neurotrophic factors in age-related loss of myenteric neurons. Aging Cell. 2006;5(3):247-57.

[112] Camilleri M, Cowen T, Koch TR. Enteric neurodegeneration in aging. Neurogastroenterol Motil. 2008;20(4):18596.
[113] Abalo R, Jose Rivera A, Vera G, Isabel Martin M. Ileal myenteric plexus in aged guinea pigs: Loss of structure and calretin in immune-reactive neurons. Neurogastroenterol Motil. 2005;17(1):123-32.

[114] Hetz S, Acikgoez A, Moll C, Jahnke HG, Robitzki AA, Metzger R, Metzger M. Age-related gene expression analysis in enteric ganglia of human colon after laser microdissection. Front Aging Neurosci. 2014;6:276.

[115] Collins J, Borojevic R, Verdu EF, Huizinga JD, Ratcliffe EM. Intestinal microbiota influences the early postnatal development of the enteric nervous system. Neurogastroenterol Motil. 2014;26(1):98-107.

[116] Kabouridis PS, Lasrado R, McCallum S, Chng SH, Snippert HJ, Clevers H, Pettersson S, Pachnis V. Microbiota controls the homeostasis of glial cells in the gut lamina propria. Neuron. 2015;85(2):289-95.

[117] McVey Neufeld KA, Mao YK, Bienenstock J, Foster JA, Kunze WA. The microbiome is essential for normal gut intrinsic primary afferent neuron excitability in the mouse. Neurogastroenterol Motil. 2013;25(2):183-8.

[118] Grasset E, Puel A, Charpentier J, Collet X, Christensen JE, Tercé F, Burcelin R. A Specific gut microbiota dysbiosis of type 2 diabetic mice induces GLP-1 resistance through an enteric no-dependent and gut-brain axis mechanism. Cell Metabolism. 2017;25(5):1075-90.

[119] Pierre JF, Barlow-Anacker AJ, Erickson CS, Heneghan AF, Leverson GE, Dowd SE, Epstein ML, Kudsk KA, Gosain A. Intestinal dysbiosis and bacterial enteroinvasion in a murine model of Hirschsprung's disease. J Pediatr Surg. 2014;49(8):1242-51.

[120] Ward NL, Pieretti A, Dowd SE, Cox SB, Goldstein AM. Intestinal aganglionosis is associated with early and sustained disruption of the colonic microbiome. Neurogastroenterol Motil. 2012;24(9):874-e400.

[121] Hyland NP, Cryan JF. Microbe-host interactions: Influence of the gut microbiota on the enteric nervous system. Dev Biol. 2016;417(2):182-7.

[122] Obata Y, Pachnis V. The effect of microbiota and the immune system on the development and organization of the enteric nervous system. Gastroenterology. 2016;151(5):836-44.

[123] Camilleri M, Madsen K, Spiller R, Greenwood-Van Meerveld B, Verne GN. Intestinal barrier function in health and gastrointestinal disease. Neurogastroenterol Motil. 2012;24(6):503-12.

[124] Köhler CA, Maes M, Slyepchenko A, Berk M, Solmi M, Lanctôt KL, Carvalho AF. The gut-brain axis, including the microbiome, leaky gut and bacterial translocation: Mechanisms and pathophysiological role in Alzheimer's disease. Curr Pharm Des. 2016;22(40):6152-66.

[125] Cani PD, Bibiloni R, Knauf C, Waget A, Neyrinck AM, Delzenne NM, Burcelin R. Changes in gut microbiota control metabolic endotoxemia-induced inflammation in high-fat diet-induced obesity and diabetes in mice. Diabetes. 2008;57(6):1470-81.

[126] Sato J, Kanazawa A, Ikeda F, Yoshihara T, Goto H, Abe H, Komiya K, Kawaguchi M, Shimizu T, Ogihara T, Tamura Y, Sakurai Y, Yamamoto R, Mita T, Fujitani Y, Fukuda H, Nomoto K, Takahashi T, Asahara T, Hirose T, Nagata S, Yamashiro Y, Watada H. Gut dysbiosis and detection of "live gut bacteria" in blood of Japanese patients with type 2 diabetes. Diabetes Care. 2014;37(8):2343-50. 
[127] Slyepchenko A, Maes M, Machado-Vieira R, Anderson G, Solmi M, Sanz Y, Berk M, Köhler CA, Carvalho AF. Intestinal dysbiosis, gut hyperpermeability and bacterial translocation: Missing links between depression, obesity and type 2 diabetes. Curr Pharm Des. 2016;22(40):6087106.

[128] Nier A, Engstler AJ, Maier IB, Bergheim I. Markers of intestinal permeability are already altered in early stages of non-alcoholic fatty liver disease: Studies in children. PLoS One. 2017;12(9):e0183282.

[129] Stevens BR, Goel R, Seungbum K, Richards EM, Holbert RC, Pepine CJ, Raizada MK. Increased human intestinal barrier permeability plasma biomarkers zonulin and FABP2 correlated with plasma LPS and altered gut microbiome in anxiety or depression. Gut. 2017. pii: gutjnl-2017-314759.

[130] Kim YR, Volpert G, Shin KO, Kim SY, Shin SH, Lee Y, Sung SH, Lee YM, Ahn JH, Pewzner-Jung Y, Park WJ, Futerman AH, Park JW. Ablation of ceramide synthase 2 exacerbates dextran sodium sulphate-induced colitis in mice due to increased intestinal permeability. J Cell Mol Med. 2017.

[131] Qi Y, Goel R, Kim S, Richards EM, Carter CS, Pepine CJ, Raizada MK, Buford TW. Intestinal permeability biomarker zonulin is elevated in healthy aging. J Am Med Dir Assoc. 2017;18(9):810.e1-810.e4.

[132] Chang J, Leong RW, Wasinger VC, Ip M, Yang M, Phan TG. Impaired intestinal permeability contributes to ongoing bowel symptoms in patients with inflammatory bowel disease and mucosal healing. Gastroenterol. 2017;153(3):723-31.

[133] Mu Q, Kirby J, Reilly CM, Luo XM. Leaky gut as a danger signal for autoimmune diseases. Front Immunol. 2017;8:598

[134] Hall KE, Proctor DD, Fisher L, Rose S. American gastroenterological association future trends committee report: Effects of aging of the population on gastroenterology practice, education, and research. Gastroenterology. 2005;129(4):1305-38.

[135] O’Mahony D, O'Leary P, Quigley EM. Aging and intestinal motility: A review of factors that affect intestinal motility in the aged. Drugs Aging. 2002;19(7):515-27.

[136] Phillips RJ, Powley TL. Innervation of the gastrointestinal tract: Patterns of aging. Auton Neurosci. 2007;136(1-2):119.

[137] Mullin JM, Valenzano MC, Verrecchio JJ, Kothari R. Ageand diet-related increase in transepithelial colon permeability of Fischer 344 rats. Dig Dis Sci. 2002;47(10):2262-70.

[138] Annaert P, Brouwers J, Bijnens A, Lammert F, Tack J, Augustijns P. Ex vivo permeability experiments in excised rat intestinal tissue and in vitro solubility measurements in aspirated human intestinal fluids support age-dependent oral drug absorption. Eur J Pharm Sci. 2010;39(1-3):15-22.

[139] Al-Sadi RM, Ma TY. IL-1beta causes an increase in intestinal epithelial tight junction permeability. J Immunol. 2007;178(7):4641-9.

[140] Koga T, McGhee JR, Kato H, Kato R, Kiyono H, Fujihashi $\mathrm{K}$. Evidence for early aging in the mucosal immune system. J Immunol. 2000;165(9):5352-9.

[141] Dolle ME, Kuiper RV, Roodbergen M, Robinson J, de Vlugt S, Wijnhoven SWS, Beems RB, de la Fonteyne L, de With P, van der Pluijm I, Niedernhofer LJ, Hasty P, Vijg J, Hoeijmakers JHJ, van Steeg H. Broad segmen- tal progeroid changes in short-lived Ercc1(-/Delta7) mice. Pathobiol Aging Age Relat Dis. 2011;1:7219.

[142] Meier J, Sturm A. The intestinal epithelial barrier: Does it become impaired with age? Dig Dis. 2009;27(3):240-5.

[143] Britton E, McLaughlin JT. Aging and the gut. Proc Nutr Soc. 2013;72(1):173-7.

[144] Newton JL, Jordan N, Pearson J, Williams GV, Allen A, James OF. The adherent gastric antral and duodenal mucus gel layer thins with advancing age in subjects infected with Helicobacter pylori. Gerontology. 2000;46(3): 153-57.

[145] Valentini L, Ramminger S, Haas V, Postrach E, Werich M, Fischer A, Koller M, Swidsinski A, Bereswill S, Lochs H, Schulzke JD. Small intestinal permeability in older adults. Physiol Rep. 2014;2(4):e00281.

[146] Ahmad R, Sorrell MF, Batra SK, Dhawan P, Singh AB. Gut permeability and mucosal inflammation: Bad, good or context dependent. Mucosal Immunol. 2017;10(2): 307-17.

[147] Thevaranjan N, Puchta A, Schulz C, Naidoo A, Szamosi JC, Verschoor CP, Loukov D, Schenck LP, Jury J, Foley KP, Schertzer JD, Larché MJ, Davidson DJ, Verdú EF, Surette MG, Bowdish DM. Age-associated microbial dysbiosis promotes intestinal permeability, systemic inflammation, and macrophage dysfunction. Cell Host Microbe. 2017;21(4):455-66.e4.

[148] Donohoe DR, Garge N, Zhang X, Sun W, O'Connell TM, Bunger MK, Bultman SJ. The microbiome and butyrate regulate energy metabolism and autophagy in the mammalian colon. Cell Metab. 2011;13(5):517-26.

[149] Hamer HM, Jonkers D, Venema K, Vanhoutvin S, Troost FJ, Brummer RJ. The role of butyrate on colonic function. Aliment Pharmacol Ther. 2008;27(2):104-19.

[150] Comalada M, Bailon E, de Haro O, Lara-Villoslada F, Xaus J, Zarzuelo A, Galvez J. The effects of short-chain fatty acids on colon epithelial proliferation and survival depend on the cellular phenotype. J Cancer Res Clin Oncol. 2006;132(8):487-97.

[151] Chambers AF, Groom AC, MacDonald IC. Dissemination and growth of cancer cells in metastatic sites. Nat Rev Cancer. 2002;2(8):563-72.

[152] Tiihonen K, Ouwehand AC, Rautonen N. Human intestinal microbiota and healthy aging. Ageing Res Rev. 2010;9(2):107-16.

[153] Sokol H, Seksik P, Furet JP, Firmesse O, Nion-Larmurier I, Beaugerie L, Cosnes J, Corthier G, Marteau P, Doré J. Low counts of Faecalibacterium prausnitzii in colitis microbiota. Inflamm Bowel Dis. 2009;15(8):1183-9.

[154] Maslowski KM, Mackay CR. Diet, gut microbiota and immune responses. Nature Immunol. 2011;12(1):5-9.

[155] Brahe LK, Astrup A, Larsen LH. Is butyrate the link between diet, intestinal microbiota and obesity-related metabolic diseases? Obes Rev. 2013;14(12):950-9.

[156] Gao Z, Yin J, Zhang J, Ward RE, Martin RJ, Lefevre M, Cefalu WT, Ye J. Butyrate improves insulin sensitivity and increases energy expenditure in mice. Diabetes. 2009;58(7):1509-17.

[157] De Vadder F, Kovatcheva-Datchary P, Goncalves D, Vinera J, Zitoun C, Duchampt A, Bäckhed F, Mithieux G. Microbiota-generated metabolites promote metabolic benefits via gut-brain neural circuits. Cell. 2014;156(12):84-96. 
[158] Dinan TG, Cryan JF. Gut instincts: Microbiota as a key regulator of brain development, ageing and neurodegeneration. J Physiol. 2017;595(2):489-503.

[159] Westfall S, Lomis N, Kahouli I, Dia SY, Singh SP, Prakash S. Microbiome, probiotics and neurodegenerative diseases: Deciphering the gut brain axis. Cell Mol Life Sci. 2017; doi:10.1007/s00018-017-2550-9

[160] Mackowiak PA. Recycling Metchnikoff: Probiotics, the intestinal microbiome and the quest for long life. Front Public Health. 2013;1:52.

[161] Kau AL, Ahern PP, Griffin NW, Goodman AL, Gordon JI. Human nutrition, the gut microbiome and the immune system. Nature. 2011;474(7351):327-36.

[162] Gibson GR and Roberfroid MB. Dietary modulation of the human colonic microbiota: Introducing the concept of prebiotics. J Nutr. 1995;125(6):1401-12.

[163] Toward R, Montandon S, Walton G, Gibson GR. Effect of prebiotics on the human gut microbiota of elderly persons. Gut Microbes. 2012;3(1):57-60.

[164] Vulevic J, Drakoularakou A, Yaqoob P, Tzortzis G, Gibson GR. Modulation of the fecal microflora profile and immune function by a novel trans-galactooligosaccharide mixture (B-GOS) in healthy elderly volunteers. Am J Clin Nutr. 2008;88(5):1438-46.

[165] Candore G, Balistreri CR, Colonna-Romano G, Grimaldi MP, Lio D, Listi F, Scola L, Vasto S, Caruso C. Immunosenescence and anti-immunosenescence therapies: The case of probiotics. Rejuvenation Res. 2008;11(2):425-32.

[166] Nagata S, Asahara T, Ohta T, Yamada T, Kondo S, Bian L, Wang C, Yamashiro Y, Nomoto K. Effect of the continuous intake of probiotic-fermented milk containing Lactobacillus casei strain Shirota on fever in a mass outbreak of norovirus gastroenteritis and the faecal microflora in a health service facility for the aged. $\mathrm{Br} \mathrm{J}$ Nutr. 2011;106(4):549-56.

[167] Nagpal R, Kumar A, Kumar M, Behare PV, Jain S, Yadav H. Probiotics, their health benefits and applications for developing healthier foods: A review. FEMS Microbiol Lett. 2012;334(1):1-15.

[168] Lahtinen SJ, Tammela L, Korpela J, Parhiala R, Ahokoski H, Mykkanen H, Salminen SJ. Probiotics modulate the Bifdobacterium microbiota of elderly nursing home residents. Age(Dordr). 2009;31(1):59-66.

[169] Lahtinen SJ, Forssten S, Aakko J, Granlund L, Rautonen N, Salminen S, Viitanen M, Ouwehand AC. Probiotic cheese containing Lactobacillus rhamnosus HN001 and Lactobacillus acidophilus NCFM ${ }^{\circledR}$ modifies subpopulations of fecal lactobacilli and Clostridium difficile in the elderly. Age (Dordr). 2012;34(1):133-43.

[170] Walton GE, van den Heuvel EGHM, Kosters MHW, Rastall RA, Tuohy KM, Gibson GR. A randomised crossover study investigating the effects of galactooligosaccharides on the faecal microbiota in men and women over 50 years of age. Br J Nutr. 2012;107(10):1466-75.

[171] Hickson M, D'Souza AL, Muthu N, Rogers TR, Want S, Rajkumar C, Bulpitt CJ. Use of probiotic Lactobacillus preparation to prevent diarrhoea associated with antibiotics: Randomised double blind placebo controlled trial. BMJ. 2007;335(7610):80.

[172] Pitkala KH, Strandberg TE, Finne Soveri UH, Ouwehand AC, Poussa T, Salminen S. Fermented cereal with specific bifidobacteria normalizes bowel movements in elderly nursing home residents. A randomized, controlled trial. J Nutr Health Aging. 2007;11(4):305-11.

[173] An HM, Baek EH, Jang S, Lee DK, Kim MJ, Kim JR, Lee KO, Park JG, Ha NJ. Efficacy of lactic acid bacteria (LAB) supplement in management of constipation among nursing home residents. J Nutr. 2010;9(5).

[174] Guillemard E, Tondu F, Lacoin F, Schrezenmeir J. Consumption of a fermented dairy product containing the probiotic Lactobacillus casei $\mathrm{DN}-114001$ reduces the duration of respiratory infections in the elderly in a randomised controlled trial. Br J Nutr. 2010;103(1):58-68.

[175] Gill HS, Rutherfurd KJ, Cross ML, Gopal PK. Enhancement of immunity in the elderly by dietary supplementation with the probiotic Bifidobacterium lactis HNO19. Am J Clin Nutr. 2001;74(6):833-9.

[176] Matsumoto M, Benno Y. Anti-inflammatory metabolite production in the gut from the consumption of probiotic yogurt containing Bifidobacterium animalis subsp. lactis LKM512. Biosci Biotechnol Biochem. 2006;70(6): 1287-92.

[177] Moro-Garcia MA, Alonso-Arias R, Baltadjieva M, Fernandez Benitez C, Fernandez Barrial MA, Diaz Ruisanchez E, Alonso Santos R, Alvarez Sánchez M, Saavedra Mijan J, Lopez-Larrea C. Oral supplementation with Lactobacillus delbrueckii subsp. bulgaricus 8481 enhances systemic immunity in elderly subjects. Age (Dordr). 2013;35(4):1311-26.

[178] Duncan SH, Flint HJ. Probiotics and prebiotics and health in ageing populations. Maturitas. 2013;75(1):44-50.

[179] Yang H-Y, Liu S-L, Ibrahim SA, Zhao L, Jiang J-L, Sun W-F, et al. Oral administration of live Bifidobacterium substrains isolated from healthy centenarians enhanced immune function in BALB/c mice. Nutr Res. 2009;29(4):281-9.

[180] Dominguez-Bello MG, Blaser MJ, Ley RE, Knight R. Development of the human gastrointestinal microbiota and insights from high-throughput sequencing. Gastroenterology. 2011;140(6):1713-9.

[181] Shen Q, Shang N, Li P. In vitro and in vivo antioxidant activity of Bifidobacterium animalis 01 isolated from centenarians. Curr Microbiol. 2011;62(4):1097-103.

[182] Davis LM, Martinez I, Walter J, Caitlin G, Hutkins RW. Barcoded pyrosequencing reveals that consumption of galactooligosaccharides results in a highly specific bifidogenic response in humans. PLoS One. 2011;6(9): e25200.

[183] Kleessen B, Sykura B, Zunft HJ, Blaut M. Effects of inulin and lactose on fecal microflora, microbial activity, and bowel habit in elderly constipated persons. Am J Clin Nutr. 1997;65(5):1397-402.

[184] Bouhnik Y, Achour L, Paineau D Riottot M, Attar A, Bornet F. Four-week short chain fructo-oligosaccharides ingestion leads to increasing fecal bifidobacteria and cholesterol excretion in healthy elderly volunteers. Nutr J. 2007;6(42).

[185] Vulevic J, Juric A, Tzortzis G, Gibson GR. A mixture of trans-galactooligosaccharides reduces markers of metabolic syndrome and modulates the fecal microbiota and immune function of overweight adults. J Nutr. 2013;143(3):324-31

[186] Neyrinck AM, Possemiers S, Druart C, Van de Wiele T, De Backer F, Cani PD, Larondelle Y, Delzenne NM. Prebiotic effects of wheat arabinoxylan related to the increase 
in bifidobacteria, Roseburia and Bacteroides/Prevotella in diet-induced obese mice. PLoS One. 2011;6(6):e20944.

[187] Hooda S, Boler BM, Serao MC, Brulc JM, Staeger MA, Boileau TW, Dowd SE, Fahey GC Jr, Swanson KS. 454 pyrosequencing reveals a shift in fecal microbiota of healthy adult men consuming polydextrose or soluble corn fiber. J Nutr. 2012;142(7):1259-65.

[188] Haenen D, Zhang J, Souza da Silva C, Bosch G, van der Meer IM, van Arkel J, van den Borne JJ, Pérez Gutiérrez O, Smidt H, Kemp B, Müller M, Hooiveld GJ. A diet high in resistant starch modulates microbiota composition, SCFA concentrations, and gene expression in pig intestine. J Nutr. 2013;143(3):274-83.

[189] Geier MS, Butler RN, Howarth GS. Probiotics, prebiotics and synbiotics: A role in chemoprevention for colorectal cancer? Cancer Biol Ther. 2006;5(10):1265-9.

[190] Koenigsknecht MJ, Young VB. Faecal microbiota transplantation for the treatment of recurrent Clostridium difficile infection: Current promise and future needs. Curr Opin Gastroenterol. 2013;29(6):628-32.

[191] Rao K, Young VB. Fecal microbiota transplantation for the management of Clostridium difficile infection. Infect Dis Clin North Am. 2015;29(1):109-22.

[192] Tacke D, Wisplinghoff H, Kretzschmar A, Farowski F, Koehler P, Herweg J, Cornely OA, Vehreschild MJ. First implementation of frozen, capsulized faecal microbiota transplantation for recurrent Clostridium difficile infection into clinical practice in Europe. Clin Microbiol Infect. 2015;2015;21(11):e82-4.

[193] Smits LP, Bouter KE, de Vos WM, Borody TJ, Nieuwdorp M. Therapeutic potential of fecal microbiota transplantation. Gastroenterology. 2013;145(5):946-53.

[194] Shanahan F, Quigley EM. Manipulation of the microbiota for treatment of IBS and IBD-challenges and controversies. Gastroenterology. 2014;146(6):1554-63.

[195] Konturek PC, Haziri D, Brzozowski T, Hess T, Heyman S, Kwiecien S, Konturek SJ, Koziel J. Emerging role of fecal microbiota therapy in the treatment of gastrointestinal and extra-gastrointestinal diseases. J Physiol pharmacol. 2015;66(4):483-91.

[196] Hill C, Guarner F, Reid G, Gibson GR, Merenstein DJ, Pot B, Morelli L, Canani RB, Flint HJ, Salminen S, Calder PC, Sanders ME. Expert consensus document. The International Scientific Association for Probiotics and Prebiotics consensus statement on the scope and appropriate use of the term probiotic. Nat Rev Gastroenterol Hepatol. 2014;11(8):506-14. 